\title{
Study on Mechanical Properties of Acidic and Alkaline Silty Soil by Electrochemical Impedance Spectroscopy
}

\author{
Peng Han, Pengju Han*, Yibo Yan, Xiaohong Bai \\ Tianjin University, State Key Lab Hydraul Engn Simulat \& Safety, TianJin 300350, Peoples R China \\ *E-mail: 13834569544@163.com
}

doi: $10.20964 / 2018.11 .19$

Received: 23 July 2018 / Accepted: 23 August 2018 / Published: 1 October 2018

In this study, Electrochemical Impedance Spectroscopy (EIS) was used to test $\mathrm{H}_{2} \mathrm{SO}_{4}$ and $\mathrm{NaOH}$ contaminated silty soil. To further study the mechanical properties (shear strength and compressive properties) of contaminated silty soil, an equivalent circuit model $\left(\mathrm{R}_{\mathrm{S}}\left(\mathrm{CPE}\left(\mathrm{R}_{\mathrm{t}} \mathrm{R}_{\mathrm{w}}\right)\right)\right.$ ) was established to simulate the changes in silty soil contaminated by various concentrations of $\mathrm{H}_{2} \mathrm{SO}_{4}$ and $\mathrm{NaOH}$ solutions. Experiments showed that with the increase in the amount of acid-base contaminant involved, the shear strength of the contaminated silty soil decreased, and the compressive properties increased. By analysing the equivalent circuit model, it can be observed that with the increase in the amount of acid-base contaminant involved, the solution resistance $\mathrm{R}_{\mathrm{s}}$ and charge transfer resistance $\mathrm{R}_{\mathrm{t}}$ decreased, while the diffusion admittance $Y_{O w}$ and double layer admittance $Y_{O Q}$ increased. Of these, $R_{t}$ and $Y_{O W}$ vary significantly, indicating that the resistance of the charge transfer process and diffusion process are considerably reduced, and the electrochemical reaction becomes easier. As a result, more and more minerals in the silty soil medium become soft plastic products during the electrochemical reaction. Simultaneously, various organic and inorganic cement materials between the soil particles are dissolved, and the connection between the silty soil particles is weakened. Eventually, the compressibility of silty soil increases and the shear strength is considerably reduced.

Keywords: silty soil, shear strength, compressive properties, EIS

\section{FULL TEXT}

(C) 2018 The Authors. Published by ESG (www.electrochemsci.org). This article is an open access article distributed under the terms and conditions of the Creative Commons Attribution license (http://creativecommons.org/licenses/by/4.0/). 